\title{
FROM ARMANI TO ZARA: IMPRESSION FORMATION BASED ON FASHION STORE PATRONAGE
}

Fine and fast fashion are ever more converging, due to the commoditization of the fashion luxury sector (termed "Zarafication" by D'Aveni, 2010: 2) on the one hand, and the "massclusivity" trend in fashion retailing on the other hand. Just as consumers buy luxury fashion brands to express or enhance their self-image, so can they be expected to patronize fashion stores with a personality positioning that matches their self-concept (Sirgy et al., 2000). This paper studies the effect of fashion store patronage on impression formation processes, addressing the following research question: "Do people use store personality characteristics to infer personality of the store's patrons?". In particular, the two extremes in Fiske and Neuberg's (1990) impression formation continuum model, are studied: (1) "category-based processing" in which the perceiver has a general impression of the typical store patron (cf. study one) and (2) "piecemeal processing" in which the perceiver uses multiple salient cues to infer associations (cf. study two).

In study one, twelve well-known fashion stores are evaluated in terms of five fashion store personality (FSP) dimensions (i.e., sophistication, conspicuousness, innovativeness, chaos, and agreeableness) by approximately 55 respondents each (Belgian female respondents, age: 25-40). Each respondent rates six stores and is furthermore asked to imagine the typical patron of each of these stores and to evaluate this kind of person in terms of the Big Five (B5) personality factors. A seemingly unrelated regression analysis is used to estimate the effect of each of the five FSP dimensions on the store patron's B5 personality trait attributions. The resulting significant regression coefficients indicate, for example, that: (1) patrons of an agreeable fashion store are attributed with an agreeable personality themselves, (2) fashion store innovativeness is an antecedent of patron attributed extraversion and openness, (3) patrons of sophisticated stores are perceived to be conscientious, and (4) chaotic stores evoke patron associations of neuroticism.

Study two consists of a between-subjects experimental design $(\mathrm{n}=322$; Belgian female respondents, age: 25-40), in which Fennis and Pruyn's (2007) research on clothing brand personality transfers, is partly replicated in the context of fashion retailing. Ten experimental conditions are based on a picture showing a woman carrying a shopping bag; the only difference being the store from which the bag originates. Shopping bags can act as "walking billboards", promoting the retail brand and they can be expected to "project the personality of the person carrying the bag" (Prendergast et al., 2001: 476). Respondents are therefore asked to evaluate the target person in terms of the B5. The results of a MANOVA indicate a significant main effect of the store patronage cue on perceivers' impression of the depicted woman's conscientiousness, extraversion, and agreeableness. Finally, a correspondence analysis allows for a visual representation of the statistically significant association between fashion stores and their patrons' personality types. For instance, shopping at H\&M seems to contribute to the perception of being a pleasant person. Apparently, besides "dress to impress", consumers should also mind the contribution of external cues of store patronage to the way they are perceived by others.

References available upon request. 